\title{
The Implication of Hypoxia and Cancer Stem Cells on Tumor Vasculogenesis
}

\author{
Nermeen Moustafa* \\ Department of Pharmacy, Queen's University Belfast, UK \\ *Corresponding author: Nermeen Moustafa nmoustafa@cellbiolondon.co.uk \\ To Cite This Article: Nermeen Moustafa, The Implication of Hypoxia and Cancer Stem Cells on Tumor Vasculogenesis. Am J Biomed Sci \& Res. 2019 \\ - 6(4). AJBSR.MS.ID.001048. DOI: 10.34297/AJBSR.2019.06.001048.
}

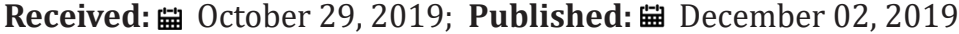

\begin{abstract}
Tumors vasculature and lymphogensis are crucial for growth and metastasis. Tumor vessels are characterized by irregular structure with higher permeability than normal vessels. This irregularity in shape results in micro-regional hypoxia due to inadequate oxygen supply to tumor cells. Triggered by hypoxia and mediated by Cancer Stem Cells (CSCs), both angiogenesis and Vasculogenic Mimicry (VM) were found in many solid tumors including breast cancer, melanoma, Head and Neck Squamous Cell Carcinoma (HNSCC).
\end{abstract}

\section{Tumor Angiogenesis and Cancer Stem Cells (CSCs)}

Tumor angiogenesis develops due to injury in the basement membrane in tissue and creation of hypoxia thus releasing angiogenic factors that activate endothelial cells to migrate, proliferate and stabilize [1]. The activation of the angiogenic factors such as Vascular Endothelial Growth Factor (VEGF), Basic Fibroblast Growth Factor (bFGF) and angiogenin and the down- regulation of the angiogenic inhibitors such as angiostatin, interferon, platelet factor 4 and endostatin together regulate tumor angiogenesis [2]. Tumor neovascularization is often linked to stemness through the differentiation of CSCs to endothelial cells. CSCs in melanoma differentiate into endothelial-like cells when cultured in specific endothelial cell growth medium [3,4]. Studies explained the implication of CSCs in angiogenesis [3-5].

The human melanoma cell line, WM115, expresses angiogenic factors including VEGF, VEGFR-2, Ang1/2 and Tie2 along with melanoma specific CSCs signaling proteins such as Notch $[4,5]$. Moreover, it was found that CSCs promote EGFR-Akt-Smad signalling resulting in ID3 regulated cytokine induction which drives tumor angiogenesis [3]. As in other tumors, the CSC marker, CD133, is also important for angiogenesis in melanoma. CD133+ melanoma specific CSCs play an important role in the formation of functional tubules and in the maintenance of endothelial cell alignment [4].

Rapid uncontrolled tumor growth leads to increased oxygen demand due to a surge in cellular metabolism, resulting in the eventual formation of hypoxic microenvironment [6]. Hypoxia is considered a key driving force of tumor progression, significantly impacting tumor cell differentiation [7]. In addition, hypoxia stimulates the activation of transcription factors and signaling pathways involved in angiogenesis and cell survival, which further promote tumor growth and metastasis $[8,9]$.

\section{Vasculogenic Mimicry is Triggered by Hypoxia}

Anti-angiogenic cancer drugs that target tumor vasculature result in hypoxic stress within the tumor microenvironment [10]. Hypoxic conditions can trigger the formation of independent non-angiogenic vascular-like structure in a few solid tumors, a phenomenon is known as Vasculogenic Mimicry (VM) [11]. VM was first described in 1999 using an aggressive melanoma cell model that acquired endothelial-like properties by de-differentiating into multiple cellular phenotypes. The endothelial-like characteristics acquired by these cells resulted in the development of vascularlike structures described as vasculogenic-like matrix-embedded networks [12]. These vasculogenic-like networks contained plasma and red blood cells suggesting that this matrix could contribute to tumor blood circulation $[12,13]$. VM networks were found to be enriched in laminin and lined by tumor cells [12-14]. Importantly, there was no evidence for the presence of endothelial cells within these matrix-rich channels, identifying VM as a fully independent process from angiogenesis [12]. 
In aggressive tumors, an increased risk of metastasis is associated with an abundance of VM-associated matrix-rich networks in tumor tissue, consequently correlating with poor clinical outcomes in patients $[12,15,16]$. In hepatocellular carcinoma, hypoxia promoted VM through transcriptional coactivation of Bcl-2 and Twist1 where their nuclear co-expression is correlated to VE expression [17]. Also, the expression of hypoxiainducible factor HIF-2 $\alpha$ up-regulates VE-cadherin [18]. VE-cadherin expression triggers signaling pathways which in turn activates VM in melanoma [14]. Knockdown of VE-cadherin results in the inhibition of VM in aggressive melanomas [19].

\section{The Role of Cscs in Vasculogenic Mimicry}

Cell plasticity plays an important role in the neovascularization process, associated with extracellular matrix remodeling [20]. The de-differentiation of cancer cells to an embryonic or stem-like cell phenotype results in tumor plasticity resulting in VM forming tumor that express endothelial specific genes [21]. CSCs exhibit a plasticity that enables their trans-differentiation into cell types of variable linage including endothelial-like and highly replicative tumor cells [22,23]. Furthermore, CSCs were observed in VMforming tumors including melanoma, glioblastoma, OSCC and breast cancer $[3,19,24,25]$.

Aggressive melanoma cells undergoing VM express genes relevant to stem cells as well as alternative cell phenotypes. The plasticity, multipotency and embryonic-like phenotype defines these cells as Malignant Melanoma Stem Cells (MMSCs) [26]. In breast cancer cells, holoclones (CSC clones highly expressing CD133) were able to form a well-established VM tubular structure while meroclones and paraclones (well differentiated clones) failed to establish VM networks which highlights the important role CSCs play in the formation of VM [27].

\section{Conclusion}

Anti-angiogenic agents have been widely accepted as an effective anticancer therapy. However, conventional antiangiogenic treatments exhibit limited efficacy in preventing tumor progression [28]. Common anti-angiogenic drugs like angiostatin and endostatin inhibit endothelial cell proliferation and enhance endothelial apoptosis resulting in a hypoxic microenvironment due to reduced vascular density [29]. Deficiencies in oxygen and nutrients contribute to VM formation as an alternative supply route, compensating for the loss of vasculature [30]. Tumors undergoing VM are typically highly aggressive, malignant and resistant to anti-angiogenic therapeutics [31,32]. Consequently, routine antiangiogenic therapies can, in part, contribute to disease progression. Therefore, it is crucial to develop new treatments capable of targeting different types of tumor vasculature; angiogenesis and VM, rather than conventional anti-angiogenics.

\section{References}

1. Denekamp J (1993) Angiogenesis, neovascular proliferation and vascular pathophysiology as targets for cancer therapy. The British Journal of Radiology 66(783): 181-196.
2. Dameron KM, Volpert OV, Tainsky MA, Bouck N (1994) Control of angiogenesis in fibroblasts by p53 regulation of thrombospondin 1 . Science 265(5178) 1582-1584.

3. Bussolati B, Bruno S, Grange C, Ferrando U, Camussi G (2008) Identification of a tumour-initiating stem cell population in human renal carcinomas. The FASEB Journal 22(10): 3696-3705.

4. Kumar D, Kumar S, Gorain M, Tomar D, Patil HS, et al. (2016) Notch1MAPK Signaling Axis Regulates CD133+ Cancer Stem Cell-Mediated Melanoma Growth and Angiogenesis. Journal of Investigative Dermatology 136(12): 2462-2474.

5. Monzani E, Facchetti F, Galmozzi E, Corsini E, Benetti A, et al. (2007) Melanoma contains CD133 and ABCG2 positive cells with enhanced tumourigenic potential. European Journal of Cancer 43(5): 935-946.

6. Mohamed KM, Le A, Duong H, Wu Y, Zhang Q et al. (2004) Correlation between VEGF and HIF-1 $\alpha$ expression in human oral squamous cell carcinoma. Experimental and molecular pathology 76(2): 143-152.

7. Sakamoto K, Imanishi Y, Tomita T, Shimoda M, Kameyama K, et al. (2012) Overexpression of SIP1 and downregulation of E-cadherin predict delayed neck metastasis in stage I/II oral tongue squamous cell carcinoma after partial glossectomy. Annals of surgical oncology 19(2): 612-619.

8. Fong GH (2008) Mechanisms of adaptive angiogenesis to tissue hypoxia. Angiogenesis 11(2): 121-140.

9. Ghosh G, Subramanian IV, Adhikari N, Zhang X, Joshi HP, et al. (2010) Hypoxia- induced microRNA-424 expression in human endothelial cells regulates HIF- $\alpha$ isoforms and promotes angiogenesis. Journal of Clinical Investigation 120(11): 4141-4154.

10. Muz, B, de la Puente P, Azab F, Azab AK (2015) The role of hypoxia in cancer progression, angiogenesis, metastasis, and resistance to therapy. Hypoxia (Auckland NZ) Dove Press 3: 83-92.

11. Bridgeman VL, Vermeulen PB, Foo S, Bilecz A, Daley F, et al. (2017) Vessel co-option is common in human lung metastases and mediates resistance to anti-angiogenic therapy in preclinical lung metastasis models. The Journal of pathology 241(3): 362-374.

12. Maniotis AJ, Folberg R, Hess A, Seftor EA, Gardner LM, et al. (1999) Vascular Channel Formation by Human Melanoma Cells in vivo and in vitro: Vasculogenic Mimicry. The American Journal of Pathology 155: 739-752.

13. Folberg R, Hendrix MJC, Maniotis AJ (2000) Vasculogenic Mimicry and Tumour Angiogenesis. The American Journal of Pathology. Elsevier 156(2): 361-381

14.Seftor RE, Seftor EA, Koshikawa N, Meltzer PS, Gardner LM, et al. (2001) Cooperative interactions of laminin 5 gamma2 chain, matrix metalloproteinase-2, and membrane type- 1matrix/ metalloproteinase are required for mimicry of embryonic vasculogenesis by aggressive melanoma. Cancer research 61(17): 6322-6327.

15. Folberg R, Rummelt V, Parys-Van Ginderdeuren R, Hwang T, Woolson RF, et al. (1993) The Prognostic Value of Tumour Blood Vessel Morphology in Primary Uveal Melanoma. Ophthalmology 100: 13891398.

16. Sun B, Zhang S, Zhao X, ZhangW, Hao X (2004) Vasculogenic mimicry is associated with poor survival in patients with mesothelial sarcomas and alveolar rhabdomyosarcomas. International journal of oncology 25(6): 1609-1614.

17.Sun T, Sun BC, Zhao XL, Zhao N, Dong XY, et al. (2011) Promotion of tumor cell metastasis and vasculogenic mimicry by way of transcription coactivation by Bcl-2 and Twist1: A study of hepatocellular carcinoma. Hepatology 54(5): 1690-1706.

18. Le Bras A, Lionneton F, Mattot V, Lelievre E, Caetano B, et al. (2007) HIF-2 $\alpha$ specifically activates the VE-cadherin promoter independently of hypoxia and in synergy with Ets-1 through two essential ETSbinding sites. Oncogene 26(53): 7480-7489. 
19. Hendrix MJ, Seftor EA, Meltzer PS, Gardner LM, Hess AR, et al. (2001) Expression and functional significance of VEcadherin in aggressive human melanoma cells: role in vasculogenic mimicry. Proceedings of the National Academy of Sciences 98(14): 8018-8023.

20.Sood AK, Seftor EA, Fletcher MS, Gardner LM, Heidger PM, et al. (2001) Molecular Determinants of Ovarian Cancer Plasticity. The American Journal of Pathology 158(4): 1279-1288.

21. Hendrix MJ, Seftor EA, Hess AR, Seftor RE (2003) Angiogenesis: Vasculogenic mimicry and tumour-cell plasticity: lessons from melanoma. Nature Reviews Cancer 3(6): 411-421.

22. Wang R, Chadalavada K, Wilshire J, Kowalik U, Hovinga KE, et al. (2010) Glioblastoma stem-like cells give rise to tumour endothelium. Nature 468(7325): 829-833.

23. Ricci-Vitiani L, Pallini R, Biffoni M, Todaro M, Invernici G, et al. (2010) Tumour vascularization via endothelial differentiation of glioblastoma stem-like cells. Nature 468(7325): 824-828.

24. Dang D, Ramos DM (2009) Identification of \{alpha\}v\{beta\}6-positive stem cells in oral squamous cell carcinoma. Anticancer research 29(6): 2043-2049.

25. El Hallani S, Boisselier B, Peglion F, Rousseau A, Colin C, et al. (2010) A new alternative mechanism in glioblastoma vascularization: tubular vasculogenic mimicry. Brain 133(4): 973-982.

26. Schatton T, Murphy GF, Frank NY, Yamaura K, Waaga-Gasser AM, et al. (2008) Identification of cells initiating human melanomas. Nature 451(7176): 345-349.
27. Liu TJ, Sun BC, Zhao XL, Zhao XM, Sun T, et al. (2013) CD133+ cells with cancer stem cell characteristics associates with vasculogenic mimicry in triple-negative breast cancer. Oncogene. Nature Publishing Group 32(5): 544-553.

28. Van der Schaft DW, Seftor RE, Seftor EA, Hess AR, Gruman LM, et al. (2004) Effects of Angiogenesis Inhibitors on Vascular Network Formation by Human Endothelial and Melanoma Cells. JNCI Journal of the National Cancer Institute 96(19): 1473-1477.

29. Folkman J (2006) Antiangiogenesis in cancer therapy-endostatin and its mechanisms of action. Experimental Cell Research. Academic Press 312(5): 594-607.

30. Van Der Schaft DW, Hillen F, Pauwels P, Kirschmann DA, Castermans K, et al. (2005) Tumour Cell Plasticity in Ewing Sarcoma, an Alternative Circulatory System Stimulated by Hypoxia. Cancer Research 65(24): 11520-11528.

31. Lin P, Wang W, Sun BC, Cai WJ, Li L, et al. (2012) Vasculogenic mimicry is a key prognostic factor for laryngeal squamous cell carcinoma: a new pattern of blood supply. Chinese medical journal 125(19): 3445-3449.

32. Luo F, Yang K, Liu RL, Meng C, Dang RF et al. (2014) Formation of vasculogenic mimicry in bone metastasis of prostate cancer: correlation with cell apoptosis and senescence regulation pathways. Pathology, research and practice 210(5): 291-295 